\title{
Sensitivity of East Asian Climate to the Progressive Uplift and Expansion of the Tibetan Plateau Under the Mid-Pliocene Boundary Conditions
}

\author{
JIANG Dabang*1,4 (姜大膀), DING Zhongli ${ }^{2}$ (丁仲礼), Helge DRANGE ${ }^{3}$, and GAO Yongqi ${ }^{1,3}$ (郜永祺) \\ ${ }^{1}$ Nansen-Zhu International Research Centre, Institute of Atmospheric Physics, \\ Chinese Academy of Sciences, Beijing 100029 \\ ${ }^{2}$ Institute of Geology and Geophysics, Chinese Academy of Sciences, Beijing 100029 \\ ${ }^{3}$ Nansen Environmental and Remote Sensing Centre, Bergen N-5006, Norway \\ ${ }^{4}$ Max Planck Institute for Biogeochemistry, Jena 07745, Germany
}

(Received 5 July 2007; revised 4 December 2007)

\begin{abstract}
A global atmospheric general circulation model has been used to perform eleven idealized numerical experiments, i.e., TP00, TP10, ‥, TP100, corresponding to different percentages of the Tibetan Plateau altitude. The aim is to explore the sensitivity of East Asian climate to the uplift and expansion of the Tibetan Plateau under the reconstructed boundary conditions for the mid-Pliocene about 3 Ma ago. When the plateau is progressively uplifted, global annual surface temperature is gradually declined and statistically significant cooling signals emerge only in the Northern Hemisphere, especially over and around the Tibetan Plateau, with larger magnitudes over land than over the oceans. On the contrary, annual surface temperature rises notably over Central Asia and most parts of Africa, as well as over northeasternmost Eurasia in the experiments TP60 to TP100. Meanwhile, the plateau uplift also leads to annual precipitation augmentation over the Tibetan Plateau but a reduction in northern Asia, the Indian Peninsula, much of Central Asia, parts of western Asia and the southern portions of northeastern Europe. Additionally, it is found that an East Asian summer monsoon system similar to that of the present initially exists in the TP60 and is gradually intensified with the continued plateau uplift. At $850 \mathrm{hPa}$ the plateau uplift induces an anomalous cyclonic circulation around the Tibetan Plateau in summertime and two anomalous westerly currents respectively located to the south and north of the Tibetan Plateau in wintertime. In the mid-troposphere, similarto-modern spatial pattern of summertime western North Pacific subtropical high is only exhibited in the experiments TP60 to TP100, and the East Asian trough is steadily deepened in response to the progressive uplift and expansion of the Tibetan Plateau.
\end{abstract}

Key words: Tibetan Plateau, uplift, East Asian climate, mid-Pliocene, model

Citation: Jiang, D., Z. L. Ding, H. Drange, and Y. Q. Gao, 2008: Sensitivity of East Asian climate to the progressive uplift and expansion of the Tibetan Plateau under the mid-Pliocene boundary conditions. Adv. Atmos. Sci., 25(5), 709-722, doi: 10.1007/s00376-008-0709-x.

\section{Introduction}

Large-scale mountain building can essentially impact climate system through dynamical and thermodynamic effects on the tectonic timescale. However, it is difficult to deduce the influence of mountain uplift on past climate change only from geological evi- dence. Quantitative evaluation of climate change due to large-scale mountain uplift on the basis of climate models may improve our understanding on geological climate change (e.g., Ruddiman et al., 1989).

For several decades, a number of numerical experiments have been performed to investigate climatic effects of large-scale mountains. In addition to the nu-

\footnotetext{
${ }^{*}$ Corresponding author: JIANG Dabang, jiangdb@mail.iap.ac.cn
} 
merical experiments with and without mountains on a global scale (e.g., Manabe and Terpstra, 1974; Hahn and Manabe, 1975; Broccoli and Manabe, 1992; Kitoh, 1997, 2002; Liu et al., 2003), there are a few simulations to address the sensitivity of climate to global mountain height. For instance, Kutzbach et al. (1989) and Prell and Kutzbach (1992) conducted experiments without mountains, half mountains, and full mountains with the NCAR CCM series atmospheric models. Vavrus and Kutzbach (2002) used an asynchronously coupled atmosphere-ocean model to examine the response of oceanic thermohaline circulation to atmospheric $\mathrm{CO}_{2}$ enrichment and lowered topography. Recently, Abe et al. (2003, 2004, 2005) and Kitoh (2004) used global coupled atmosphere-ocean models CGCM1 and CGCM2, developed at the Meteorological Research Institute of Japan, to simulate the effect of progressive mountain uplift on both Asian climate and the tropical coupled atmosphere-ocean system over the Indian and Pacific Oceans in summer through six numerical experiments with different global mountain heights.

Besides the above numerical experiments focusing on global mountains, special attention has been paid to the climatic consequences of the Tibetan Plateau (hereinafter referred to as TP) uplift because of its huge extent and height as well as its situation (e.g., Ramstein et al., 1997; Fluteau et al., 1999). In particular, An et al. (2001) used the NCAR CCM3 to conduct five experiments with four idealized stages of the Himalayan and Tibetan Plateau altitude and then addressed the possible linkage of Asian monsoon evolution to the phases of the Himalayan and Tibetan plateau uplift. Liu and Yin (2002) examined the sensitivity of East Asian monsoon climate to idealized progressive uplift of the TP by the atmospheric model of the Center for Ocean-Land-Atmosphere (COLA). However, the climatic consequences of the uplift of the TP still remain an open question (An et al., 2001; Wang et al., 2005). Here, the authors would like to emphasize that all of the numerical experiments cited above are performed under the present boundary conditions [Although Ramstein et al. (1997) and Fluteau et al. (1999) used the reconstructed continental geography and epicontinental sea distribution for the middleto-late Miocene and early Oligocene, they did not investigate climatic consequences of the TP uplift], such as sea surface temperature, sea ice extent, continental ice extent and height, surface vegetation, and so on. Whether idealized topographical height is relatively consistent with the present boundary conditions remains neglected.

The precise history of the uplift process of the TP is still unresolved. Some investigators speculated that significant increase in elevation of portions of the TP occurred about 7.2 Ma ago (An, 2000), 8 Ma ago (Harrison et al., 1992; Molnar et al., 1993; Molnar, 2005), $10 \mathrm{Ma}$ ago (Rowley et al., 2001), 13.7-9 Ma ago (Sun et al., 2005), $11 \mathrm{Ma}$ ago (Garzione et al., 2000), $12 \mathrm{Ma}$ ago (Dettman et al., 2003), at least $15 \mathrm{Ma}$ ago (Spicer et al., 2003), and $22 \mathrm{Ma}$ ago (Guo et al., 2002). In contrast, Wang et al. (1999) deduced that the TP probably reached an elevation of 1500 meters by the latest Miocene (8-5 Ma ago), not as high as was previously thought. Moreover, there are other evidences that the TP, especially its northern portion, uplifted rapidly and extended northward and eastward at 3.6-2.6 Ma ago (Li et al., 1997; Rea et al., 1998; An, 2000; Zheng et al., 2000, 2004). As such, it now seems reasonable to assume that the main uplift of the TP occurs in the time period at least earlier than the Quaternary (e.g., Fort, 1996). As is widely known, the Earth's surface environment during the Quaternary differs greatly from the Tertiary. Of most importance is that the Northern Hemisphere glaciation was not widely developed in the Tertiary (e.g., An et al., 2001). Therefore, modeling climatic consequences of the TP uplift is relatively "unrealistic" under the present boundary conditions.

Some scientists often, at least partly, attributed a variety of reconstructed earlier-than-Quaternary climate records in East Asian domain to the uplift of the TP based on available simulation results or inference. For instance, Qiang et al. (2001) ascribed a relatively strong East Asian winter monsoon between 3.5 Ma and 3.1 Ma ago to the Pliocene uplift of the northwestern TP. Guo et al. (2004) related the most important aridification event in Asian interior, at about 3.6 Ma ago, to an uplift of portions of the TP. Zheng et al. (2004) indicated that the late Miocene and mid-Pliocene enhancement of East Asian monsoon was the result of coeval uplift episodes in the Himalayan-Tibetan region. Such reports motivate us to examine what the climatic consequences of the TP uplift are under the Pliocene boundary conditions, which are significantly different from the present day as a whole.

In an attempt to explore the influence of the uplift and expansion of the TP on East Asian climate regime in the past and to further understand the effects of the TP on the operation of the present East Asian climate system, a global atmospheric general circulation model has been used to perform a set of idealized numerical experiments in this research. The core improvement over previous experiments is the use of relatively more "realistic" mid-Pliocene boundary conditions on a global scale, instead of the modern values. Additionally, such an exercise is particularly helpful to understand the Late Cenozoic climate change in East 
Asian region since the model can reasonably reproduce many aspects of the present climate and climate change in this region.

\section{Model, boundary conditions and experi- mental design}

The global atmospheric general circulation model used here was developed at the Institute of Atmospheric Physics under the Chinese Academy of Sciences (hereinafter referred to as IAP AGCM). The model has a horizontal grid resolution of $4^{\circ}$ in latitude by $5^{\circ}$ in longitude and 9 levels, unevenly spaced, in the vertical with the top at $10 \mathrm{hPa}$. The model solves dynamic and thermodynamic equations and the continuity equations for mass and water vapor. A brief description on the IAP AGCM dynamical framework, physical processes, and land surface schemes was presented in Jiang et al. (2003), and more detail can be found in Zeng et al. (1987), Zhang (1990), Bi (1993), and Liang (1996). A series of simulations have been carried out using the model for over a decade. In particular, the IAP AGCM has been widely applied in paleoclimate field (Wang, 1994; Jiang and Zhang, 2006). For instance, Jiang et al. (2003), Ju et al. (2007) and Jiang and Liang (2008) employed the model to simulate climate at the Last Glacial Maximum and indicated that the results accord favorably with atmospheric models' outputs as derived from phase one of the PMIP (Joussaume and Taylor, 1995). Recently, the IAP AGCM was also used to simulate East Asian climate during the mid-Holocene (Wang, 2000, 2002; Wei and Wang, 2004; Jin et al., 2006), global warmth during the mid-Pliocene (Jiang et al., 2005), and East Asian climate transition during the Cenozoic (Zhang et al., 2007a,b).

The mid-Pliocene boundary conditions were used in all of the numerical experiments designed here. They are the latest version of the PRISM2 $2^{\circ} \times 2^{\circ}$ digital data set compiled by the U. S. Geological Survey's Pliocene Research, Interpretations, and Synoptic Mapping (PRISM) group (Dowsett et al., 1999), representing a reconstruction of the "average" conditions within the time period 3.29-2.97 Ma ago according to the geomagnetic polarity timescale of Berggren et al. (1995). The elements include monthly sea surface temperature and sea ice extent, coastline, continental topography, vegetation, and continental ice sheet on a global domain. The important features of the PRISM2 data set, compared to the present, can be summarized as follows: (1) greatly reduced continental ice volume with a small Greenland ice cap being the only continental ice in the Northern Hemisphere; (2) greatly reduced sea ice extent with the Arctic being season- ally ice free; (3) a positive sea level anomaly of 25 $\mathrm{m} ;$ (4) increased sea surface temperature at high latitudes; (5) expansion of evergreen forests to the margins of the Arctic Ocean, a reduction of desert area in equatorial Africa, essential elimination of polar desert and tundra regions in the Northern Hemisphere, and a small amount of deciduous vegetation being present at the edge of the Antarctic continent (Dowsett et al., 1999). Additionally, since atmospheric $\mathrm{CO}_{2}$ concentration was not too far from 315 ppmv at the midPliocene (Rind and Chandler, 1991), this value was taken in all of the experiments. Except for the aforementioned changes, other boundary conditions were kept at the present configuration.

When all boundary conditions in the IAP AGCM were adjusted to be consistent with the PRISM2 data, eleven numerical experiments were then designed to only represent varying topography within the range of $22^{\circ}-46^{\circ} \mathrm{N}$ and $60^{\circ}-110^{\circ} \mathrm{E}$. Inside the domain, the topographical altitude for each grid point was set to be $100 \%, 90 \%, \cdots$, and $10 \%$ of the PRISM2 elevation in different experiments, respectively. Additionally, a no-plateau experiment was designed, in which any grid altitude higher than 200 meters was reduced to 200 meters. Outside the domain, topographical altitude remained unchanged in all of the experiments. Hereinafter, the experiments are respectively referred to as TP100, TP90, ..., TP10, and TP00 (See Fig. 1 for East Asian topography configuration higher than 1000 meters in several experiments). Here, the TP100 can be regarded as the standard numerical experiment for the mid-Pliocene climate as already represented in Jiang et al. (2005).

It should be noted that topographical altitude in the experiments TP00 to TP60 was slowly decreased to the desired value when we ran the model in order to avoid a termination of integration due to rapid change of topography. In this research, each experiment included full seasonal cycle and lasted 12 model years, and the results reported below were averaged for the last 10 years. Statistical significance was assessed by use of a student $t$-test (99\% level) applied to the difference between each pair of experiments where the standard deviation and degrees of freedom were based on the averages of the 10 individual years. Incidentally, winter denotes December, January, and February, and summer corresponds to June, July, and August throughout this article.

\section{Result}

\subsection{Surface temperature}

Figure 2 shows that in the TP100 annual surface temperature is zonally distributed and is reduced to- 

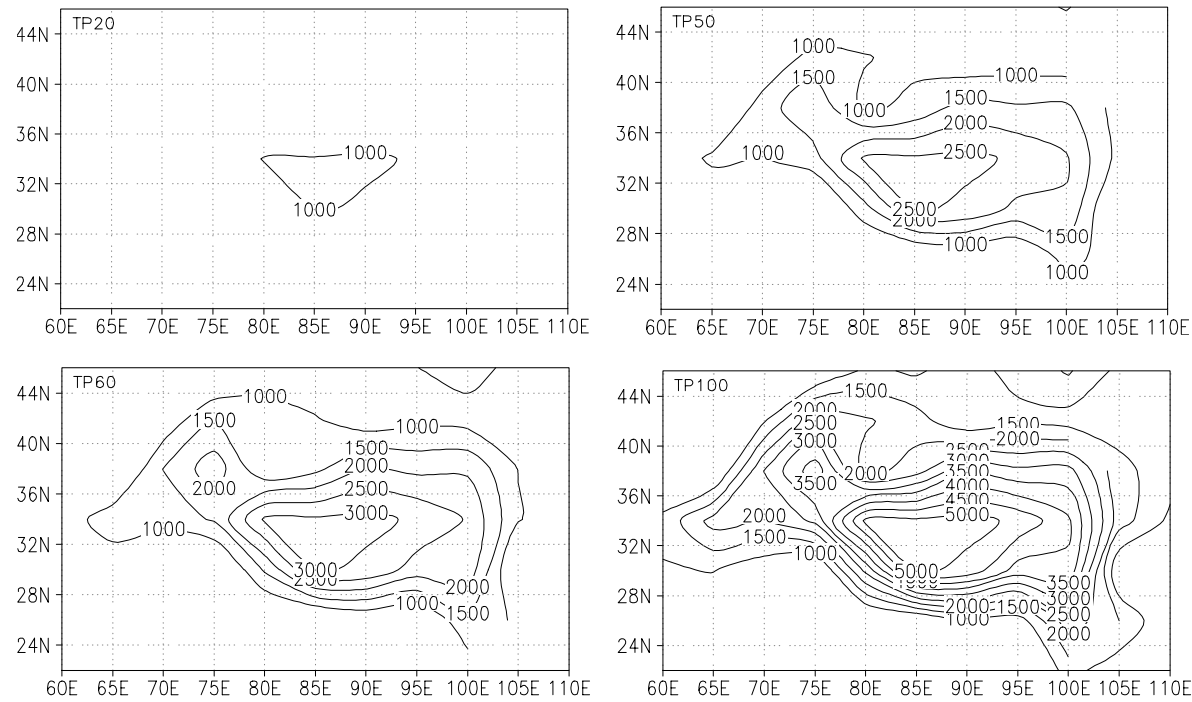

Fig. 1. Regional topography configuration of the Tibetan Plateau, and the elevation higher than 1000 meters is shown in each experiment.
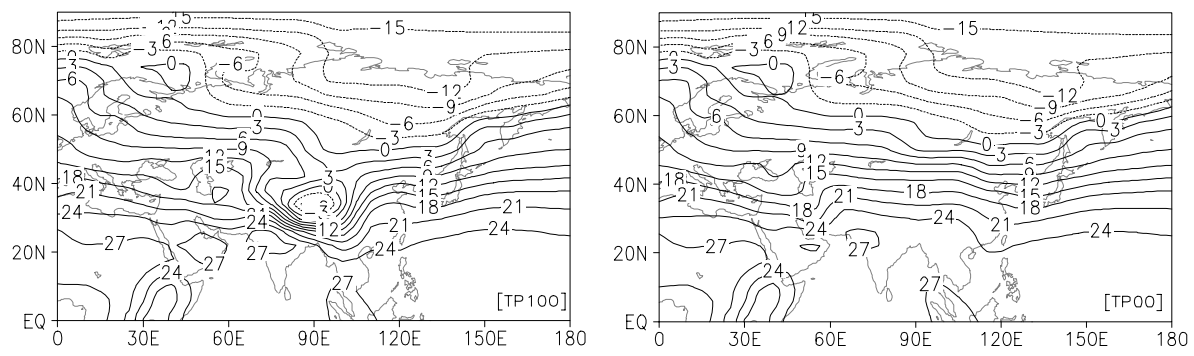

Fig. 2. Geographical distribution of annul surface temperature in the TP100 and TP00 (units: ${ }^{\circ} \mathrm{C}$ ).

ward the north; at the same time, a large extent of cooling occurs over the TP. In contrast, the above cooling center does not exist in the TP00. Moreover, the geographical distribution of seasonal surface temperature is also quite different between these two experiments. Therefore, the progressive uplift and expansion of the TP alters the spatial pattern of annual and seasonal surface temperature in East Asia significantly. Further investigation reveals that global annual surface temperature is gradually reduced with the plateau uplift. However, the cooling is not spatially uniform. Statistically significant cooling signals are only limited in the Northern Hemisphere. Comparatively, the cooling is larger over the continent than over the ocean in the Northern Hemisphere (Fig. 3). On a global scale, the cooling due to the TP uplift is mainly located within $30^{\circ}-40^{\circ} \mathrm{N}$.

The geographical distribution of annual surface temperature differences in the experiments TP10 to TP100 with respect to TP00 confirms the above features. Figure 4 shows that annual surface temperature

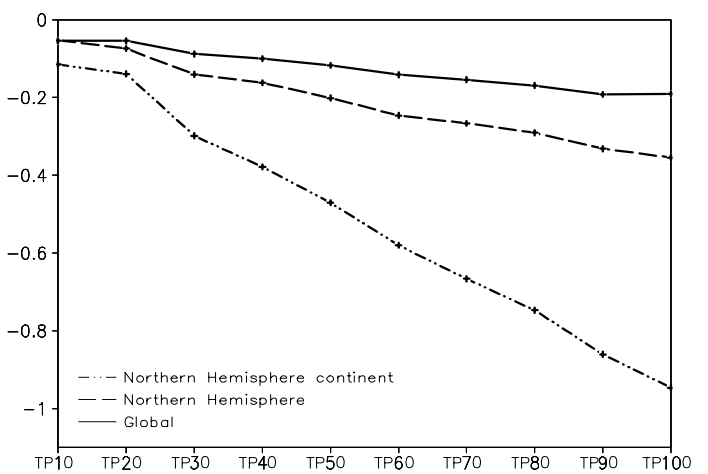

Fig. 3. Annual surface temperature differences in the TP10, TP20, $\cdots$, TP100 relative to TP00 (units: ${ }^{\circ} \mathrm{C}$ ).

is gradually declined over and around the TP, and the cooling area extends when the plateau altitude is progressively enlarged. On the contrary, annual surface temperature rises over Central Asia, most parts of Africa, and northeasternmost Eurasia in the experiments TP60 to TP100. Additionally, it is noted that 



Fig. 4. Differences of annual surface temperature in the TP10, TP20, $\cdots$, TP100 relative to TP00 (units: ${ }^{\circ} \mathrm{C}$ ), and the areas with confidence level larger than $99 \%$ are shaded. 
the influence of the plateau uplift on annual surface temperature is only limited to within East Asia in the experiments TP10 to TP50. It then extends to most parts of the Northern Hemisphere in the experiments TP60 to TP100.

On the whole, the spatial pattern of summer surface temperature differences in the experiments TP10 to TP100 with respect to TP00 is similar to the annual mean. However, summer cooling over and around the TP is relatively stronger. Furthermore, the warming over Central Asia and most parts of Africa also appears during summer in the experiments TP50 to TP100 like the annual mean, but with a much larger magnitude. It should be mentioned that summer surface temperature is usually regarded as a key factor for glaciation in the northern high latitudes because lower surface temperature allows snow and ice to build up and is consequently favorable for ice sheet development. In the IAP AGCM experiments, summer surface temperature is almost unchanged north of $70^{\circ} \mathrm{N}$. In other words, the TP uplift does not induce statistically detectable cooling in the northern high latitudes where the Quaternary glaciation is eventually formed. Of course, this topic remains open before more experiments, especially using fully coupled Earth system models, and proxy estimates are reported. During winter, surface temperature is reduced over and around the TP, with a relatively smaller magnitude than the annual mean. Meanwhile, statistically significant warming signals emerge only in much of the Indian Peninsula. Thus, the annual warming over Central Asia, most parts of Africa, and northeasternmost Eurasia is mostly attributable to summer warming (figures omitted).

\subsection{Precipitation}

The geographical distribution of annual precipitation in East Asia is mainly characterized by a large extent of relatively high values, about $2-4 \mathrm{~mm} \mathrm{~d}^{-1}$, over and around the TP in the TP100. In contrast, an-

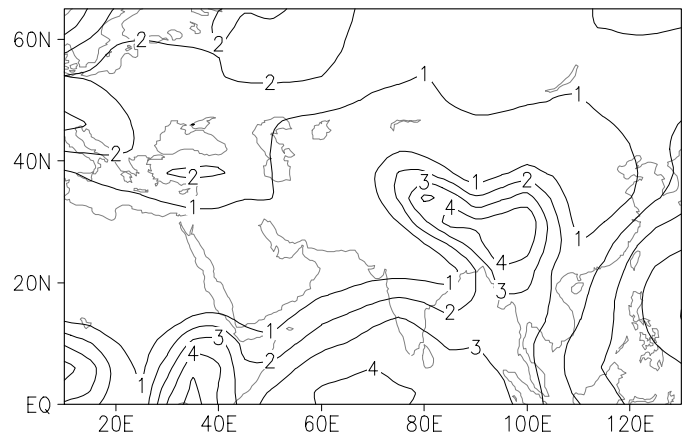

nual precipitation is zonally distributed in the TP00, with a value of about $1 \mathrm{~mm} \mathrm{~d}^{-1}$ (Fig. 5). Moreover, the spatial patterns of summer and winter precipitation are also quite different between these two experiments. For instance, intense summer precipitation, with a maximum of $10 \mathrm{~mm} \mathrm{~d}^{-1}$, over and to the southeast of the TP in the TP100 does not exist in the TP00, and the southwest-to-northeast isohyet in the former conflicts with the east-to-west isohyet in the latter in East Asia as a whole. It is found that the evolution of spatial precipitation patterns from the experiments TP00 to TP100 is progressive. Figure 6 displays that with the progressive plateau uplift, annual precipitation is gradually enhanced over the TP, whereas it is steadily reduced in northern Asia and the Indian Peninsula. Additionally, annual precipitation is gradually decreased in much of Central Asia and parts of western Asia as well as the southern parts of northeastern Europe. On the whole, the plateau uplift gives rise to dryness in Asian interior, except for over the TP.

During winter, precipitation is gradually declined in northern Asia and the Indian Peninsula when the plateau altitude is progressively uplifted. Inversely, precipitation is gradually enhanced over the TP, with a smaller extent and magnitude than the annual mean. Interestingly, the response of summer precipitation to the plateau uplift is almost unrelated to the winter case. Overall, summer precipitation is significantly enhanced over the TP, whereas it is declined in parts of Central and western Asia as well as the southern parts of northeastern Europe. In fact, the response of seasonal precipitation to the plateau uplift is quite complicated, and no uniform pattern is present. In addition, further investigations reveal that annual and seasonal precipitation responses to the progressive plateau uplift are found to comprise the contributions of both convective and large-scale precipitation (figures omitted). Therein, the proportion of largescale precipitation is dominant over the Eurasian con-

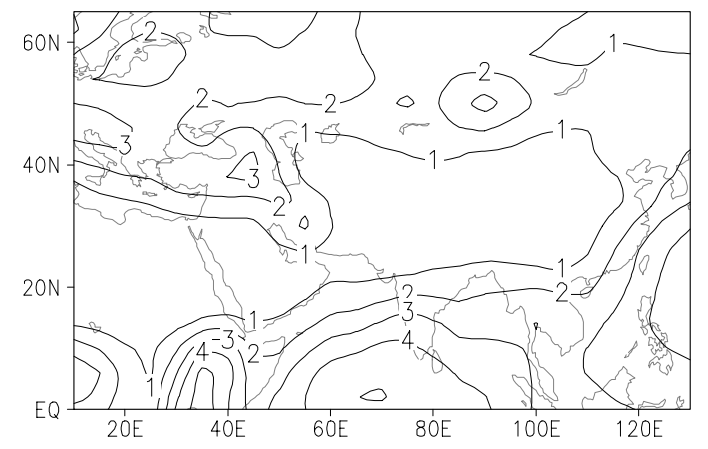

Fig. 5. Geographical distribution of annual precipitation in the experiments TP100 (left) and TP00 (right) (units: $\mathrm{mm} \mathrm{d}^{-1}$ ). 

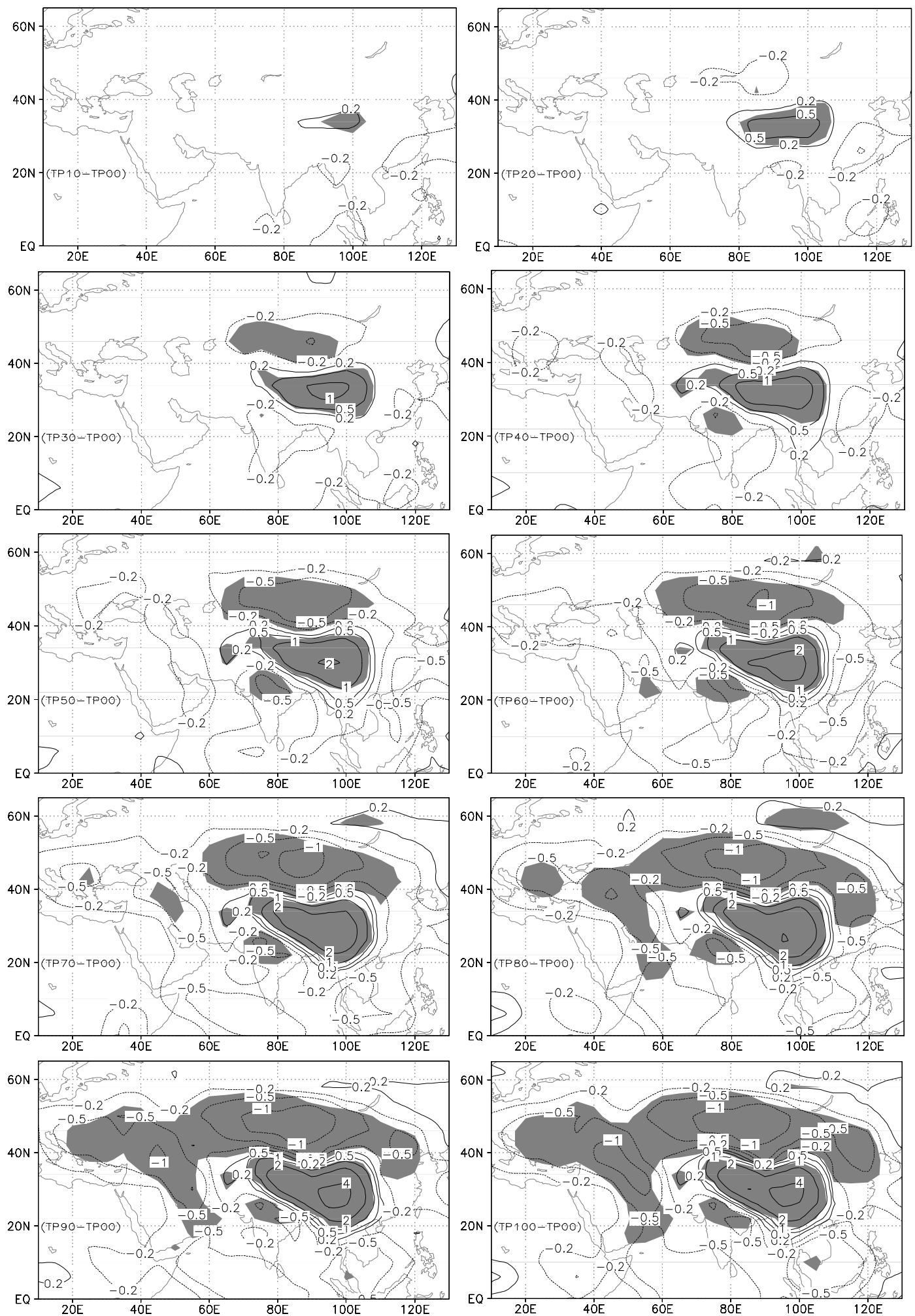

Fig. 6. Differences of annual precipitation in the TP10, TP20, ․, TP100 relative to TP00 (units: $\mathrm{mm} \mathrm{d}^{-1}$ ), and the areas with confidence level larger than $99 \%$ are shaded. 
tinent. Convective precipitation can account for $0.5-2$ $\mathrm{mm} \mathrm{d}^{-1}$ over the TP and at most $0.2 \mathrm{~mm} \mathrm{~d}^{-1}$ in other regions within the Eurasian interior. That means atmospheric general circulation, closely related to largescale precipitation pattern, alters notably when the plateau is progressively uplifted.

\subsection{East Asian atmospheric general circula- tion}

It is well known that East Asian region is characterized by monsoon climate at the present day. During winter, cold high-pressure systems are generally presented over East Asian continent, and warm low-pressure systems dominate over the North Pacific Ocean as a consequence of the difference of thermal capacity between continent and ocean. The opposite situation is characteristic during summer. The above sea level pressure pattern leads to a prevailing northerly (southerly) current in the lower troposphere during winter (summer). For several decades, how the geographical distribution of monsoon system develops from indigenous zonal pattern to the modern planetary climate system has remained an open question (Sun and Wang, 2005). As already summarized by Wang et al. (2005), at the present stage, three tectonic factors have been proposed as exercising controls over the evolution of Asian monsoon circulation on the geological timescale: the TP uplift, sea-land distribution, and oceanic gateways. However, their relative roles still remain ambiguous. Therefore, it is of particular interest to investigate the behavior of East Asian monsoon system in the present experiments.

On the whole, the influence of the plateau uplift on East Asian atmospheric general circulation is more intense during summer than winter. At present, East Asian summer monsoon (hereinafter referred to as EASM) mainly features a systematical southerly current in the eastern parts of the Chinese mainland. However, it can be seen in Fig. 7 that so-called EASM is indiscernible in the experiments TP00 to TP50. In other words, no systematical southerly current prevails in East Asia in these experiments. In contrast, a similar-to-modern EASM system is explicitly present in the experiments TP60 to TP100. Therefore, a conclusion can be drawn here that under the reconstructed mid-Pliocene boundary conditions, the EASM system is not present unless the elevation of the TP attains $60 \%$ of the PRISM2 topography. Meanwhile, it is found that EASM intensity is gradually enhanced from the experiments TP60 to TP100. As a further examination, summer mean meridional wind velocity at 850 $\mathrm{hPa}$ within $22^{\circ}-46^{\circ} \mathrm{N}$ and $100^{\circ}-125^{\circ} \mathrm{E}$ (according to both the present EASM system and grid configuration in the IAP AGCM, shown as the rectangle in Fig. 7) is used to directly detect East Asian summer wind intensity. Figure 8 indicates that East Asian summer meridional wind is gradually intensified in response to the progressive plateau uplift. It is around $0 \mathrm{~m} \mathrm{~s}^{-1}$ in the experiments TP00 to TP20 and becomes a systematical southerly current in the other experiments. However, EASM cannot be discerned in the experiments TP30 to TP50 because the southerly current is relatively weak (mean southerly wind intensity is only $0.98 \mathrm{~m} \mathrm{~s}^{-1}$ in the TP50). Of most importance is that no systematical southerly current is present in East Asia in these three experiments (see Fig. 7). Based on Figs. 7 and 8, it can be judged that EASM is initially present in the TP60 and is gradually intensified with the continued plateau uplift.

Meanwhile, it is found that an anomalous cyclonic circulation appears and is gradually intensified around the TP during summer in the experiments TP20 to TP100. As is well known, heat and low-pressure generally dominates over East Asian continent during summer. The plateau uplift can give rise to an intensified heating effect there, which further reinforces the heat and low-pressure and consequently induces an anomalous cyclonic circulation around the TP. In addition, an anomalous easterly current initially appears in the south of the Bay of Bengal in the TP50 and then gradually covers South Asia westward to East Africa north of the equator in the experiments TP60 to TP100. Moreover, the anomalous easterly current turns to the north within $40^{\circ}-60^{\circ} \mathrm{E}$ and joins in the southern branch of the cyclonic circulation cited above. Besides these changes, the southerly current is significantly strengthened in northeastern Asia in the experiments TP60 to TP100 relative to TP00.

It should be noted that the spatial pattern of East Asian winter atmospheric circulation at $850 \mathrm{hPa}$ as reproduced under the PRISM2 boundary conditions is generally similar to the present day on a large scale (Jiang et al., 2005). Figure 9 indicates that westerlies prevail in the northern mid-latitudes, whereas easterlies prevail within $0^{\circ}-20^{\circ} \mathrm{N}$ in the TP100. Similar atmospheric circulation is present in TP00. That means that the influences of the plateau uplift on East Asian winter atmospheric circulation in the lower troposphere are quite limited on a large scale. Intercomparison among the experiments reveals that the plateau uplift can induce two anomalous westerly currents, respectively located to the south and north of the TP. Within $30^{\circ}-40^{\circ} \mathrm{N}$ and $80^{\circ}-100^{\circ} \mathrm{E}$ westerly wind generally prevails in the TP00 (Fig. 9). Logically, when the plateau elevation is enlarged, westerly wind is, at least partly, blocked by the plateau when a threshold value is surpassed. Accordingly, the atmosphere current, originally passing over the plateau, 

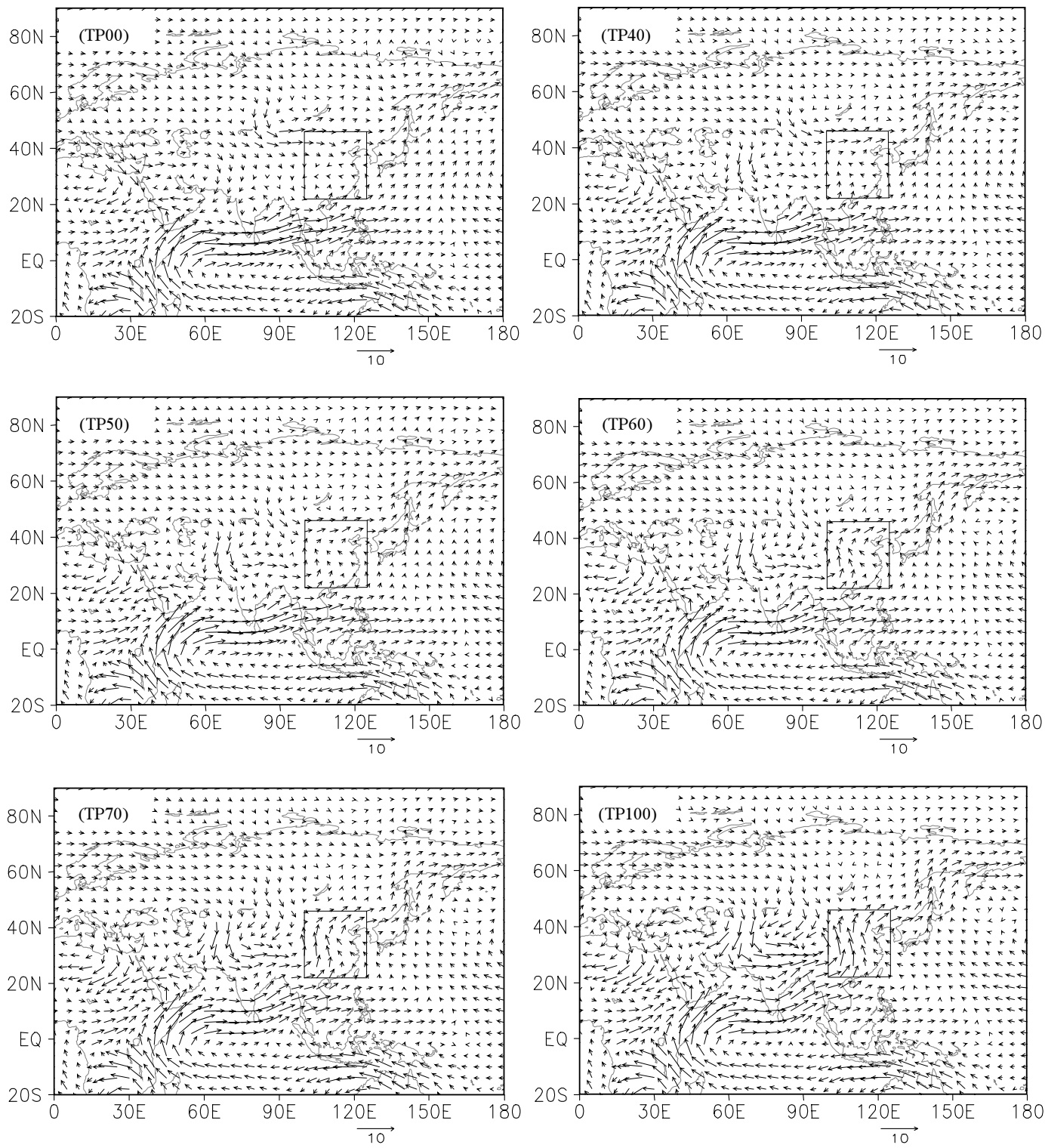

Fig. 7. Summer wind field climatology at $850 \mathrm{hPa}$ in the different experiments (units: $\mathrm{m} \mathrm{s}^{-1}$ ).

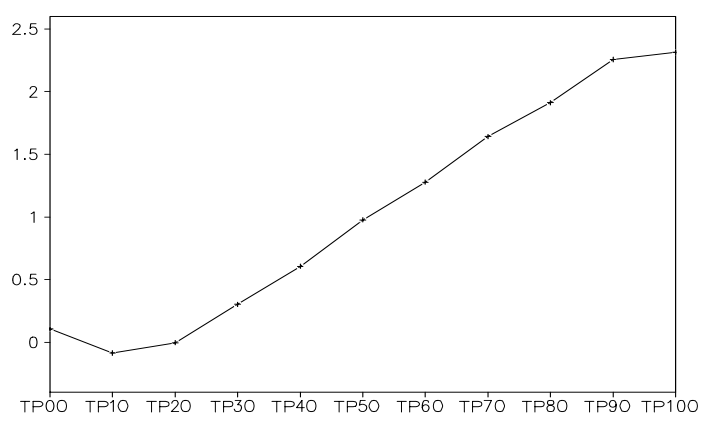

Fig. 8. Summer mean meridional wind velocity at 850 $\mathrm{hPa}$ within $22^{\circ}-46^{\circ} \mathrm{N}$ and $100^{\circ}-125^{\circ} \mathrm{E}$ (units: $\mathrm{m} \mathrm{s}^{-1}$ ).

has to go around the plateau, which therefore leads to the above two anomalous westerly currents.

The plateau uplift also impacts East Asian atmospheric circulation in the mid-troposphere (Fig. 10). In the TP100, the contour of geopotential height at 500 $\mathrm{hPa}$ is zonally distributed north of $50^{\circ} \mathrm{N}$ and is reduced northward during summer on the whole. Within $10^{\circ}$ $50^{\circ} \mathrm{N}$ it is characterized by the subtropical high over the western North Pacific Ocean with the western edge at about $110^{\circ} \mathrm{E}$, one of the key factors in the modern East Asian climate regime, and by a low value center over the TP as well as a subtropical high extending from the Bay of Bengal westward to North Africa. In contrast, both the subtropical high over the western North Pacific Ocean and the lower value center over the TP in the TP100 disappear in the TP00. Further 

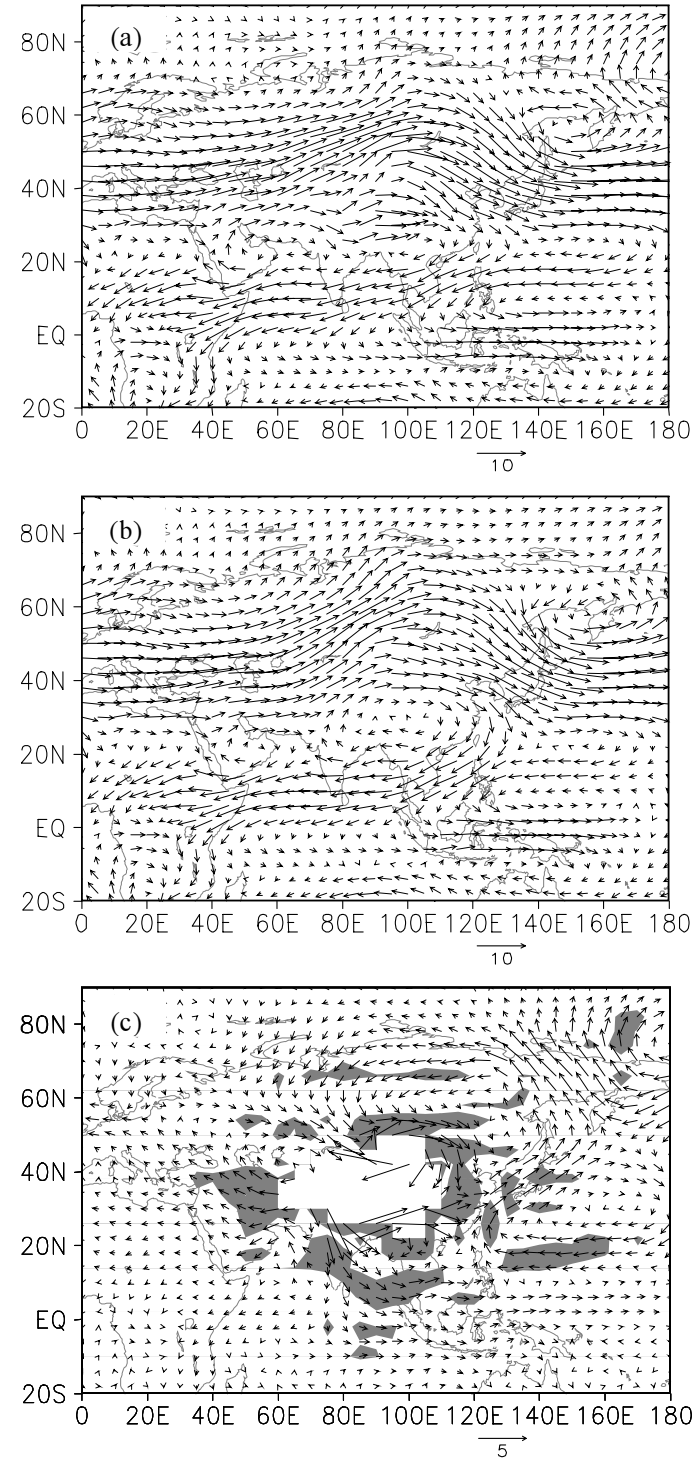

Fig. 9. Winter wind field at $850 \mathrm{hPa}$ : (a) for TP100 climatology, (b) for TP00 climatology, and (c) denotes (a) minus (b) (units: $\mathrm{m} \mathrm{s}^{-1}$ ). In (c), the areas with confidence level larger than $99 \%$ are shaded, and the regions with the elevation higher than 1500 meters are blank within the range of $22^{\circ}-46^{\circ} \mathrm{N}$ and $60^{\circ}-110^{\circ} \mathrm{E}$.

examination reveals that the spatial pattern of summer geopotential height at $500 \mathrm{hPa}$ is generally consistent, in spite of tiny difference, among the experiments TP00 to TP50, whereas similar-to-modern arrangement only exists in the experiments TP60 to TP100 (figures omitted). If we take the contour of $5800 \mathrm{gpm}$ as an approximate estimation of the extent of summer western North Pacific subtropical high (after Xue et al., 2003), the abrupt change of the contour occurs between the experiments TP50 and TP60 (Fig. 11). Therefore, the plateau uplift plays a fundamental role in shaping the present configuration of summer western North Pacific subtropical high. During winter, the climatic consequences of the plateau uplift are quite limited in the mid-troposphere in East Asian domain, and only the East Asian trough is found to gradually intensify, with a maximum value of about $40 \mathrm{gpm}$ (figures omitted).

In the upper troposphere, the plateau uplift induces two anomalous large-scale anticyclonic circulations during summer. One surrounds the TP, with a maximum value of $10 \mathrm{~m} \mathrm{~s}^{-1}$, and the other is situated over northeastern Asia, with a maximum value of $5 \mathrm{~m}$ $\mathrm{s}^{-1}$. During winter, an anomalous northwesterly current appears to the northeast of the TP, and an anomalous easterly current is presented to the south of the TP (figures omitted). Moreover, the former enhances East Asian subtropical westerly jet significantly, one of the most important atmospheric circulation systems in East Asian domain.

\section{Conclusions}

Under the reconstructed PRISM2 boundary conditions for the mid-Pliocene, about $3 \mathrm{Ma}$ ago, the IAP AGCM simulated significantly different climate conditions in East Asian domain, generally consistent with reconstructed evidence (Jiang et al., 2005, and references therein). East Asian climate scenario at the mid-Pliocene is hence quite different from the present. Therefore, the PRISM2 data provide us an opportunity to examine East Asian climate response to the progressive uplift and expansion of the TP prior to the Quaternary when the Northern Hemisphere glaciation had not widely initiated. Collectively, the primary conclusions derived from the IAP AGCM experiments could be as the following:

(1) When the TP is progressively uplifted, global annual surface temperature is gradually reduced. Statistically significant cooling signals emerge only in the Northern Hemisphere, especially over and around the $\mathrm{TP}$, at the same time with relatively larger cooling over land than over the oceans. Conversely, annual surface temperature rises over Central Asia, most parts of Africa, and northeasternmost Eurasia in the experiments TP60 to TP100. Additionally, the influence of the plateau uplift on annual surface temperature is limited to within East Asia in the experiments TP10 to TP50 and then extends to most parts of the Northern Hemisphere in the experiments TP60 to TP100.

(2) Annual precipitation is gradually enhanced over the TP, whereas it is steadily reduced in northern Asia, the Indian Peninsula, much of Central Asia and parts of western Asia as well as the southern parts of northeastern Europe. The above precipitation responses 

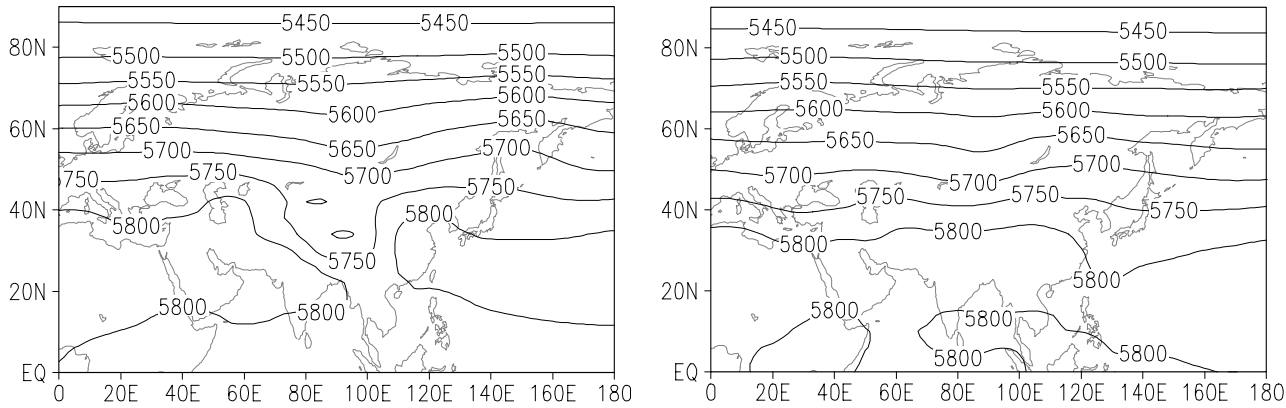

Fig. 10. Summer geopotential height climatology at $500 \mathrm{hPa}$ in the TP100 (left) and TP00 (right) (units: gpm)

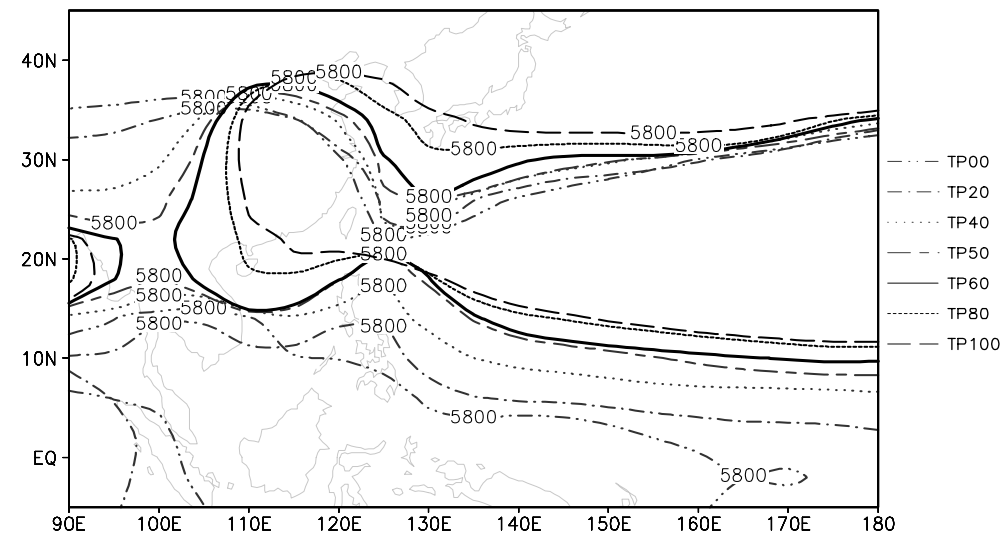

Fig. 11. The isoline of 5800 gpm during summer in the IAP AGCM experiments.

are mostly linked to atmospheric general circulation change over the Eurasian continent.

(3) In the lower troposphere, similar-to-modern EASM is initially present in the TP60 and is gradually intensified with the continued plateau uplift. During summer, an anomalous cyclonic circulation forms and is gradually intensified around the TP, and an anomalous easterly current initially appears in the south of the Bay of Bengal in the TP50 and gradually covers South Asia westward to East Africa north of the equator in the experiments TP60 to TP100. During winter, the plateau uplift induces two anomalous westerly currents respectively located to the south and north of the TP.

(4) In the mid-troposphere, a similar-to-modern spatial pattern of summer western North Pacific subtropical high is abruptly exhibited when the plateau altitude reaches $60 \%$ of the PRISM2 topography. During winter, the East Asian trough is gradually deepened in response to the plateau uplift.

As already described in the introduction section, several experiments have been performed to explore climatic effects of large-scale mountains worldwide. In circum-East Asia regions, a qualitative conclusion can be drawn from Table 1 that the presence or uplift of global mountains or the TP alone can give rise to common climatic consequences independent of models, i.e. cooling over the TP, dryness in much of the regions to the north and west of the TP, wetness over the TP, intensified East Asian monsoon circulation, and increased East Asian monsoon precipitation. The IAP AGCM results are consistent with the above as a whole. A key point can be consequently put forward that the above responses are independent of boundary conditions for the mid-Pliocene, earlier than the Quaternary, since they have been utilized in this study. Moreover, the above climatic consequences are also compatible with the basic direction of geologic records around Asian interior (Ruddiman and Kutzbach, 1989). Therefore, large-scale mountain building is indeed a key factor in the evolution of East Asian climate regime throughout the Cenozoic, at least in terms of available numerical experiments so far.

In addition, there are discrepancies among the aforementioned models's results. For instance, dramatically increased East Asian winter monsoon circulation calculated by the COLA AGCM (Liu and Yin, 2002) is not reproduced by the IAP AGCM. Furthermore, some detailed aspects are also inconsistent among the models' results, such as what the TP 
Table 1. General climatic consequences due to mountain building as derived from models.

\begin{tabular}{lll}
\hline Models & Key climatic consequences over and around East Asia & References \\
\hline NCAR-CCM0 & $\begin{array}{c}\text { The TP and Colorado plateaus' uplift leads to surface cooling over the } \\
\text { TP and North and Central Asia, intensified Asian monsoon circulation, } \\
\text { increased East Asian monsoon precipitation, dryness in the regions } \\
\text { north and west of the TP in Asian interior, and wetness over the TP. }\end{array}$ & $\begin{array}{c}\text { Kutzbach et al. (1989) } \\
\text { and Rudiman and }\end{array}$ \\
GFDL-AGCM & Global mountain existence leads to dryness in Central Asia. & Broccoli and \\
& & Manabe (1992)
\end{tabular}

threshold elevation is, $50 \%$ or $60 \%$ of the present elevation, for EASM formation. It is interesting to scrutinize different responses of climate models to the imposed similar boundary and/or forcing conditions in the context of past climate simulation. However, because of both significantly different boundary conditions and significantly or slightly different experimental designs with respect to the previous simulations, it is difficult for us to further comment on other points obtained by the IAP AGCM here.

Atmospheric GCM alone is used here as most cases in the literature, and ocean dynamics is consequently prohibited. However, striking changes in ocean state were reproduced by the MRI coupled atmosphere-ocean GCM when global mountains are progressively uplifted (Abe et al., 2004; Kitoh, 2007). In addition, climate change due to the mountain uplift will inevitably impact vegetation, and concomitant vegetation-atmosphere feedback also needs to be evaluated by coupled climate-vegetation model. Therefore, more attention should be paid to the above two aspects in the future.

Acknowledgements. The authors would like to sincerely thank Dr. Harry J. Dowsett and the PRISM group for providing the PRISM2 data set, two anonymous reviewers, Prof. Wang Huijun, and Dr. Zhang Zhongshi for constructive comments. Funding was jointly provided by the Chinese Academy of Sciences under Grant Nos. KZCX2YW-205 and KZCX3-SW-229 and the National Natural Science Foundation of China under Grant Nos. 40505017 and 40775052 .

\section{REFERENCES}

Abe, M., A. Kitoh, and T. Yasunari, 2003: An evolution of the Asian summer monsoon associated with mountain uplift - simulation with the MRI atmosphereocean coupled GCM. J. Meteor. Soc. Japan, 81, 909 933.

Abe, M., T. Yasunari, and A. Kitoh, 2004: Effects of large-scale orography on the coupled atmosphereocean system in the tropical Indian and Pacific oceans in boreal summer. J. Meteor. Soc. Japan, 82, $745-759$

Abe, M., T. Yasunari, and A. Kitoh, 2005: Sensitivity of the central Asian climate to uplift of the Tibetan Plateau in the coupled climate model (MRICGCM1). The Island Arc, 14, 378-388.

An, Z., 2000: The history and variability of the East Asian paleomonsoon climate. Quaternary Science Reviews, 19, 171-187.

An, Z., J. E. Kutzbach, W. L. Prell, and S. C. Porter, 2001: Evolution of Asian monsoons and phased uplift of the Himalaya-Tibetan Plateau since late Miocene time. Nature, 411, 62-66.

Berggren, W. A., D. V. Kent, C. C. Swisher, and M. P. Aubry, 1995: A revised Cenozoic geochronology and chronostratigraphy. Geochronology, Time Scales and Global Stratigraphic Correlation, W. A. Berggren et al., Eds., Spec. Publ. SEPM Soc. Sediment. Geol., 54, 129-212.

Bi, X., 1993: IAP 9-level atmospheric general circulation model and climate simulation. Ph. D. dissertation, 
Institute of Atmospheric Physics, Chinese Academy of Sciences, Beijing, 210pp. (in Chinese)

Broccoli, A. J., and S. Manabe, 1992: The effects of orography on midlatitude Northern Hemisphere dry climates. J. Climate, 5, 1181-1201.

Dettman, D. L., X. Fang, C. N. Garzione, and J. Li, 2003: Uplift-driven climate change at $12 \mathrm{Ma}$ : A long $\delta^{18} \mathrm{O}$ record from the NE margin of the Tibetan plateau. Earth and Planetary Science Letters, 214, 267-277.

Dowsett, H., J. Barron, R. Poore, R. Thompson, T. Cronin, S. Ishman, and D. Willard, 1999: Middle Pliocene paleoenvironmental reconstruction: PRISM2. U. S. Geological Survey Open File Report, 99-535. [Available at http://pubs.usgs.gov/of/1999/of99-535]

Fluteau, F., G. Ramstein, and J. Besse, 1999: Simulating the evolution of the Asian and African monsoons during the past $30 \mathrm{Myr}$ using an atmospheric general circulation model. J. Geophys. Res., 104(D10), 11995-12018.

Fort, M., 1996: Late Cenozoic environmental changes and uplift on the northern side of the central Himalaya: a reappraisal from field data. Palaeogeography, Palaeoclimatology, Palaeoecology, 120, 123-145.

Garzione, C. N., J. Quade, P. G. DeCelles, and N. B. English, 2000: Predicting paleoelevation of Tibet and the Himalaya from $\delta^{18} \mathrm{O}$ vs. altitude gradients in meteoric water across the Nepal Himalaya. Earth and Planetary Science Letters, 183, 215-229.

Guo, Z., and Coauthors, 2002: Onset of Asian desertification by 22 Myr ago inferred from loess deposits in China. Nature, 416, 159-163.

Guo, Z., S. Peng, Q. Hao, P. E. Biscaye, Z. An, and T. Liu, 2004: Late Miocene-Pliocene development of Asian aridification as recorded in the red-earth formation in northern China. Global and Planetary Change, 41, 135-145.

Hahn, D. G., and S. Manabe, 1975: The role of mountains in the South Asian monsoon circulation. J. Atmos. Sci., 32, 1515-1541.

Harrison, T. M., P. Copeland, W. S. F. Kidd, and A. Yin, 1992: Raising Tibet. Science, 255, 1663-1670.

Jiang, D., and Z. Zhang, 2006: Paleoclimate modelling at the Institute of Atmospheric Physics, Chinese Academy of Sciences. Adv. Atmos. Sci., 23(6), 10401049.

Jiang, D., and X. Liang, 2008: Attribution of East Asian climate at the last glacial maximum. Quaternary Sciences, 28(3), 491-501. (in Chinese with English abstract)

Jiang, D., H. J. Wang, H. Drange, and X. Lang, 2003: Last Glacial Maximum over China: Sensitivities of climate to paleovegetation and Tibetan ice sheet. J. Geophys. Res., 108(D3), 4102, doi: 10.1029/2002JD002167.

Jiang, D., H. J. Wang, Z. Ding, X. Lang, and H. Drange, 2005: Modeling the middle Pliocene climate with a global atmospheric general circulation model. J. Geophys. Res., 110, D14107, doi:
10.1029/2004JD005639.

Jin, L., H. J. Wang, F. Chen, and D. Jiang, 2006: A possible impact of cooling over the Tibetan Plateau on the mid-Holocene East Asian monsoon climate. Adv. Atmos. Sci., 23(4), 543-550, doi: 10.1007/s00376006-0543-y.

Ju, L., H. J. Wang, and D. Jiang, 2007: Simulation of the Last Glacial Maximum climate over East Asia with a regional climate model nested in a general circulation model. Palaeogeography, Palaeoclimatology, Palaeoecology, 248, 376-390.

Joussaume, S., and K. E. Taylor, 1995: Status of the Paleoclimate Modeling Intercomparison Project (PMIP). Proc. First International AMIP Scientific Conference, Tech. Doc. WMO/TD-732, W. L. Gates, Ed., World Meteorol. Organ., Geneva, Switzerland, 425430.

Kitoh, A., 1997: Mountain uplift and surface temperature changes. Geophys. Res. Lett., 24, 185-188.

Kitoh, A., 2002: Effects of large-scale mountains on surface climate - A coupled ocean-atmosphere general circulation model study. J. Meteor. Soc. Japan, 80, $1165-1181$.

Kitoh, A., 2004: Effects of mountain uplift on East Asian summer climate investigated by a coupled atmosphere-ocean GCM. J. Climate, 17, 783-802.

Kitoh, A., 2007: ENSO modulation by mountain uplift. Climate Dyn., 28, 781-796.

Kutzbach, J. E., P. J. Guetter, W. F. Ruddiman, and W. L. Prell, 1989: Sensitivity of climate to Late Cenozoic uplift in southern Asia and the American West: numerical experiments. J. Geophys. Res., 94(D15), 18393-18407.

Li, J., and Coauthors, 1997: Late Cenozoic magnetostratigraphy (11-0 Ma) of the Dongshanding and Wangjiashan sections in the Longzhong Basin, western China. Geologie en Mijnbouw, 76, 121-134.

Liang, X., 1996: Description of a nine-level grid point atmospheric general circulation model. Adv. Atmos. Sci., 13, 269-298.

Liu, X., J. E. Kutzbach, Z. Liu, Z. An, and L. Li, 2003 The Tibetan Plateau as amplifier of orbital-scale variability of the East Asian monsoon. Geophys. Res. Lett., 30(16), 1839, doi:10.1029/2003GL017510.

Liu, X., and Z. Yin, 2002: Sensitivity of East Asian monsoon climate to the uplift of the Tibetan Plateau. Palaeogeography, Palaeoclimatology, Palaeoecology, 183, 223-245.

Manabe, S., and T. B. Terpstra, 1974: The effects of mountains on the general circulation of the atmosphere as identified by numerical experiments. J. Atmos. Sci., 31, 3-42.

Molnar, P., 2005: Mio-Pliocene growth of the Tibetan Plateau and evolution of East Asian climate. Palaeontologia Electronica, 8, 1-23.

Molnar, P., P. England, and J. Martinod, 1993: Mantle dynamics, uplift of the Tibetan Plateau, and the Indian monsoon development. Rev. Geophys., 31, 357396. 
Prell, W. L., and J. E. Kutzbach, 1992: Sensitivity of the Indian monsoon to forcing parameters and implications for its evolution. Nature, 360, 647-652.

Qiang, X. K., Z. X. Li, C. M. Powell, and H. B. Zheng, 2001: Magnetostratigraphic record of the Late Miocene onset of the East Asian monsoon, and Pliocene uplift of northern Tibet. Earth and Planetary Science Letters, 187, 83-93.

Ramstein, G., F. Fluteau, J. Besse, and S. Joussaume, 1997: Effect of orogeny, plate motion and land-sea distribution on Eurasian climate change over the past 30 million years. Nature, 386, 788-795.

Rea, D. K., H. Snoeckx, and L. H. Joseph, 1998: Late Cenozoic eolian deposition in the North Pacific: Asian drying, Tibetan uplift, and cooling of the northern hemisphere. Paleoceanography, 13, 215224.

Rind, D., and M. A. Chandler, 1991: Increased ocean heat transports and warmer climate. J. Geophys. Res., 96, 7437-7461.

Rowley, D. B., R. T. Pierrehumbert, and B. S. Currie, 2001: A new approach to stable isotope-based paleoaltimetry: Implications for paleoaltimetry and paleohypsometry of the High Himalaya since the Late Miocene. Earth and Planetary Science Letters, 188, 253-268.

Ruddiman, W. F., and J. E. Kutzbach, 1989: Forcing of late Cenozoic northern hemisphere climate by plateau uplift in southern Asia and the American West. J. Geophys. Res., 94(D15), 18409-18427.

Ruddiman, W. F., W. L. Prell, and M. E. Raymo, 1989: Late Cenozoic uplift in southern Asia and the American West: Rationale for general circulation modeling experiments. J. Geophys. Res., 94, 18379-18391.

Spicer, R. A., N. B. W. Harris, M. Widdowson, A. B. Herman, S. Guo, P. J. Valdes, J. A. Wolfe, and S. P. Kelley, 2003: Constant elevation of southern Tibet over the past 15 million years. Nature, 421, 622-624.

Sun, J., R. Zhu, and Z. An, 2005: Tectonic uplift in the northern Tibetan Plateau since 13.7 Ma ago inferred from molasse deposits along the Altyn Tagh Fault. Earth and Planetary Science Letters, 235, 641-653.

Sun, X., and P. Wang, 2005: How old is the Asian monsoon system?-Palaeobotanical records from China. Palaeogeography, Palaeoclimatology, Palaeoecology, 222, 181-222.

Vavrus, S., and J. E. Kutzbach, 2002: Sensitivity of the thermohaline circulation to increased $\mathrm{CO}_{2}$ and lowered topography. Geophys. Res. Lett., 29, 1546, 10.1029/2002GL014814.

Wang, H. J., 1994: Modelling the January and July cli- mate of 9000 years before present. Adv. Atmos. Sci. 11, 319-326.

Wang, H. J., 2000: The seasonal climate and low frequency oscillation in the simulated mid-Holocene megathermal climate. Adv. Atmos. Sci., 17, 445-457.

Wang, H. J., 2002: The mid-Holocene climate simulated by a grid-point AGCM coupled with a biome model. Adv. Atmos. Sci., 19, 205-218.

Wang, J., Y. Wang, Z. Liu, J. Li, and P. Xi, 1999: Cenozoic environmental evolution of the Qaidam Basin and its implications for the uplift of the Tibetan Plateau and the drying of central Asia. Palaeogeography, Palaeoclimatology, Palaeoecology, 152, 37-47.

Wang, P., S. Clemens, L. Beaufort, P. Braconnot, G. Ganssen, Z. Jian, P. Kershaw, and M. Sarnthein, 2005: Evolution and variability of the Asian monsoon system: State of the art and outstanding issues. Quaternary Science Reviews, 24, 595-629.

Wei, J., and H. J. Wang, 2004: A possible role of solar radiation and ocean in the mid-Holocene East Asian monsoon climate. Adv. Atmos. Sci., 21, 1-12.

Xue, F., D. Jiang, X. Lang, and H. J. Wang, 2003: Influence of Mascarene high and Australian high on summer monsoon in East Asia: Ensemble simulation. Adv. Atmos. Sci., 20, 799-809.

Zeng, Q., C. Yuan, X. Zhang, X. Liang, and N. Bao, 1987: A global grid-point general circulation model. In collection of papers presented at the WMO/IUGG NWP Symposium, World Meteorol. Soc., Geneva, $421-430$

Zhang, X., 1990: Dynamical framework of IAP nine-level atmospheric general circulation model. Adv. Atmos. Sci., 7, 66-77.

Zhang, Z., H. J. Wang, Z. Guo, and D. Jiang, 2007a: Impacts of tectonic changes on the reorganization of the Cenozoic paleoclimatic patterns in China. Earth and Planetary Science Letters, 257, 622-634.

Zhang, Z., H. J. Wang, Z. Guo, and D. Jiang, 2007b: What triggers the transition of palaeoenvironmental patterns in China, the Tibetan Plateau uplift or the Paratethys Sea retreat? Palaeogeography, Palaeoclimatology, Palaeoecology, 245, 317-331.

Zheng, H., C. M. Powell, D. K. Rea, J. Wang, and P. Wang, 2004: Late Miocene and mid-Pliocene enhancement of the East Asian monsoon as viewed from the land and sea. Global and Planetary Change, 41, 147-155.

Zheng, H., C. M. Powell, Z. An, J. Zhou, and G. Dong, 2000: Pliocene uplift of the northern Tibetan Plateau. Geology, 28, 715-718. 